\title{
TECNOLOGIAS E LETRAMENTO VISUAL COM STOP MOTION NA EDUCAÇÃO BÁSICA: EXPERIÊNCIAS METODOLÓGICAS COM CARTAS NARRATIVAS
}

\author{
Nuria Pons Vilardell CAMAS \\ Eduardo FOFONCA ${ }^{\text {ii }}$ \\ Andrei Rafael GALKOWSKI ${ }^{\mathrm{iii}}$
}

\begin{abstract}
RESUMO
Este artigo apresenta resultados de uma pesquisa que identifica a percepção de um grupo de docentes sobre a adoção de imagens e da linguagem fotográfica no contexto sala de aula. A pesquisa de abordagem qualitativa (LUDKE; ANDRÉ, 2011; CHIZZOTTI, 2008), tem como métodos a observação participante e a análise das experiências ocorridas no âmbito de sala de aula, considerando as narrativas dos docentes participantes de um curso de formação continuada. Os resultados evidenciam que os sujeitos reconhecem a necessidade da aplicação das diferentes tecnologias em sala de aula para explorar variadas linguagens artísticas. Sendo assim, com a adoção da linguagem fotográfica e das tecnologias digitais em sala de aula, são apontadas inadequações pedagógicas e de estrutura física dos cenários educativos.
\end{abstract}

PALAVRAS-CHAVE: Tecnologias digitais; Fotografia; Stop motion; Letramento visual.

\author{
TECHNOLOGIES AND VISUAL LETTERING WITH STOP MOTION IN THE \\ FORMATTIVE CONTEXT OF BASIC EDUCATION TEACHING: EXPERIENCES \\ REVEALED THROUGH NARRATIVE LETTERS
}

\begin{abstract}
This article presents results of a research that identifies the perception of a group of teachers about the adoption of images and photographic language in the classroom context. The research with a qualitative approach (LUDKE; ANDRE, 2011; CHIZZOTTI, 2008), uses participant observation and analysis of experiences that took place in the classroom as methods, considering the narratives of teachers participating in a continuing education course. The results show that the subjects recognize the need to apply different technologies in the classroom to explore different artistic languages. Therefore, with the

\footnotetext{
${ }^{\text {i }}$ Doutorado em Educação: Currículo pela Pontifícia Universidade Católica de São Paulo. Professora Associada na Universidade Federal do Paraná, onde atua no Departamento de Teoria e Prática de Ensino e no Programa de Mestrado em Educação: Teoria e Prática de Ensino. E-mail: nuriapons@ gmail.com.

ii Doutorado em Educação, Arte e História da Cultura pela Universidade Presbiteriana Mackenzie, SP, Pósdoutorado em Educação, Comunicação e Tecnologia pelo Programa de Educação da Universidade do Estado de Santa Catarina. Professor Pesquisador do Programa de Mestrado em Educação: Teoria e Prática de Ensino da Universidade Federal do Paraná. E-mail: eduardofofonca@gmail.com.

iii Mestre em Educação: Teoria e Prática de Ensino pela Universidade Federal do Paraná. É professor efetivo na Educação Básica, na disciplina de Artes na Rede Municipal de Ensino de Biguaçú - SC. E-mail: andrei.galkowski@hotmail.com.
} 
adoption of photographic language and digital technologies in the classroom, pedagogical and physical structure inadequacies of educational scenarios are pointed out.

KEYWORDS: Digital technologies; Photography; Stop motion; Visual literacy.

\section{TECNOLOGÍAS Y LETRAS VISUALES CON STOP MOTION EN EDUCACIÓN BÁSICA: EXPERIENCIAS METODOLÓGICAS CON GRÁFICOS NARRATIVOS}

\section{RESUMEN}

Este artículo presenta resultados de una investigación que identifica la percepción de un grupo de docentes sobre la adopción de imágenes y lenguaje fotográfico en el contexto del aula. La investigación con enfoque cualitativo (LUDKE; ANDRÉ, 2011; CHIZZOTTI, 2008), utiliza como métodos la observación participante y el análisis de experiencias ocurridas en el aula, considerando las narrativas de los docentes que participan en un curso de educación continua. Los resultados muestran que los sujetos reconocen la necesidad de aplicar diferentes tecnologías en el aula para explorar diferentes lenguajes artísticos. Por tanto, con la adopción del lenguaje fotográfico y las tecnologías digitales en el aula, se señalan las deficiencias de la estructura física y pedagógica de los escenarios educativos.

PALABRAS CLAVE: Tecnologías digitales; Fotografía; Stop Motion; Alfabetización visual.

\section{INTRODUÇÃO}

A comunicação e a interação com a sociedade e com o mundo não ocorrem somente mediante a linguagem escrita e oral. De acordo com o pensamento de Pillotto et al. (2009), dáse, também, por intermédio das expressões sonora, espacial, visual, social, corporal, entre outras. Desse modo, torna-se muito importante que os sujeitos interajam por meio das múltiplas expressões e linguagens, justamente por estarem inseridos num contexto sociocultural.

Assim, ao analisarmos o contexto escolar da Educação Básica, têm-se como ponto de partida as exigências contemporâneas do ensino de Arte, e nesse aspecto podemos ressaltar que é cada vez mais necessária à docência a utilização de uma abordagem atualizada ao sabor dos multiletramentos e das exigências contemporâneas no ensino de Arte para explorar diferentes linguagens artísticas em sala de aula, entre elas: a música, a dança, o teatro e as artes plásticas. No que diz respeito ao ensino de Arte atual, a Base Nacional Comum Curricular (BNCC), trata a Arte como componente curricular obrigatório, composto pelas linguagens da música, teatro, dança e artes visuais, como subcomponentes.

Logo, observamos que, no ensino de Arte atual, o professor desse campo de conhecimento, embora muitas vezes tenha uma formação específica para uma determinada 
linguagem (artes plásticas, música, teatro ou dança), necessita utilizar em sala de aula as diferentes linguagens, que, segundo Maciel (2016), oportunizam aos discentes não apenas conhecimento, mas uma fonte para o desenvolvimento da sensibilidade e da inspiração para a expressão concreta do estudante. Para tanto, o uso de variadas linguagens artísticas em sala de aula pode colaborar para a construção e o desenvolvimento de letramentos diversos que, de acordo com Paduan et al. (2017), são campos de exercício para práticas de multiletramentos e, pela natureza que possuem, fazem interagir múltiplos aspectos da percepção intelectual e da percepção sensível, permitindo dialogar com conteúdos de áreas distintas.

Nesse sentido, Maciel (2016) destaca que a Arte pode ser aplicada aos discentes de várias formas, constituindo-se de um letramento que pode dialogar com o uso das tecnologias digitais (TD) e outras áreas do conhecimento. Considera-se, portanto, a conexão da Arte com outros conhecimentos e, por meio uso das TD, pode-se interagir com as quatro linguagens artísticas (música, teatro, dança e artes visuais) para cooperar com os diferentes letramentos.

No tocante ao uso de diferentes tecnologias na sala de aula, conforme Camas et al. (2013), o docente tem experienciado novos modos de produzir, utilizar TD para desenvolver um possível web currículo, planejar e avaliar sua prática pedagógica que envolva as distintas linguagens/semioses e culturas mobilizadas nas práticas sociais midiatizadas pelas TD. Em face do exposto, torna-se necessário elucidar que, na ótica de Almeida e Valente (2014), o web currículo pode apontar para um estudo que vislumbre a construção de ações pedagógicas que abrangem as distintas linguagens/semioses e culturas mobilizadas nas práticas sociais midiatizadas pelas TD. Busca-se analisar os sentidos de um currículo que colabore para essa prática e possibilite novos sentidos. Para tanto, deve-se compreender de forma aprofundada acerca dessa realidade, tanto no trabalho no interior da universidade com a formação docente quanto no cotidiano da prática da Educação Básica.

Diante desses fatores, pensando na Educação Básica, surgiu nossa questão de pesquisa: qual é a percepção de um grupo de docentes de Arte do Ensino Fundamental a respeito do uso da linguagem fotográfica e de imagens no contexto de sala de aula?

Para respondermos a tal questão, desenvolvemos e aplicamos um curso de formação para professores para que pudéssemos compreender a importância de elementos que poderão adotar a linguagem fotográfica na prática pedagógica, além do uso de diferentes tecnologias e do letramento visual no contexto de sala de aula. Assim, optamos por realizar o curso de formação continuada no âmbito da rede municipal de ensino da cidade de São Bento do Sul-SC 
ocorrido no mês de Maio de 2018. Ademais, por se tratar de um espaço onde diferentes experiências puderam ser vivenciadas nesse período de formações continuadas, houve uma constante mediação com a docência que atua na Educação Básica, dialogando sobre suas dificuldades, currículo, planejamentos, entre outras abordagens que foram tecendo de forma não linear os encontros dialógicos formativos.

Portanto, sabemos que, para responder ao questionamento que propomos, outras questões de apoio surgirão, tais como: as dificuldades com a estrutura oferecida pelas escolas para a efetivação do uso das TD em sala de aula, bem como se havia um entendimento dos docentes acerca da necessidade do uso de diferentes tecnologias em sala de aula e sua indispensável discussão curricular.

\section{A LinguAgem FOtográfica E DE ANIMAÇÃo EM SALA DE AULA: DIFERENTES LETRAMENTOS}

Ao explorar a linguagem fotográfica em sala de aula, sempre fora abordado que o docente de Arte pode trabalhar essa linguagem de variadas formas e com diversas estratégias. Nesse caso, pode-se usá-la como modo de estudo e produção de retratos, diferentes releituras artísticas, formas de representações de gêneros da pintura, animações em Stop Motion. O pensamento de Carvalho (2017) mostra que a linguagem fotográfica é precursora de visualidades e ocasiona mudanças em outras linguagens, e como tal linguagem mudou no decorrer do tempo, tornando-se, nos dias de hoje, uma linguagem muito utilizada.

$\mathrm{Na}$ qualidade de linguagem imagética e como elemento enriquecedor do letramento visual, Afonso (2014) destaca que se torna um elemento pedagógico e formativo importante para a compreensão discente por buscar afeiçoar a percepção imagética do mundo e estimular a constante criatividade. Consideramos, contudo, em nossa pesquisa que a linguagem de animação do Stop Motion passou a ser um desdobramento da linguagem fotográfica, justamente por utilizar imagens fotográficas em sua construção.

Nesse sentido, torna-se apreciativo verificar que, para Purves (2011), a linguagem de animação em Stop Motion é concebida como uma técnica de criar a ilusão de movimento por meio da gravação, quadro a quadro, da manipulação de um objeto sólido ou imagem de recorte em um cenário físico espacial. Outras técnicas seguem o mesmo processo, mas com uma 
sucessão de imagens ou desenhos gerados por meio de um computador. Portanto, se as imagens que estão em sequência forem semelhantes, o cérebro as unirá, dando a impressão de movimento.

No que concerne ao seu aparecimento, linguagem, conforme Magalhães (2015), surgiu concomitantemente ao cinema e aos primeiros filmes de animação foram feitos com objetos em Stop Motion. De acordo com o pensamento de Zubler, Zanin e Ayres (2016), o efeito desse tipo de animação é obtido por meio da captura de diversos registros fotográficos de um mesmo objeto. Todavia, entre uma fotografia e outra, realizam-se pequenas alterações nos movimentos do objeto ou cenários. Cada imagem registrada recebe o nome de quadro, e em uma produção profissional são utilizados vinte e cinco a trinta quadros por segundo. Entretanto, em animações amadoras, a partir de dez quadros já se obtêm resultados satisfatórios.

Por se tratar de uma linguagem que pode utilizar objetos de fácil acesso e manuseio, conforme Magalhães (2015), no espaço escolar é possível produzir uma animação em Stop Motion usando cenários construídos com cartolinas, bonecos de massinha simples e com fundo infinito com papel-cartão branco para eliminar cantos indesejáveis ou fixar objetos.

Não obstante, para que essa linguagem seja utilizada com fins pedagógicos, torna-se necessário ao professor o emprego de diferentes letramentos e multiletramentos. Portanto, é importante entendermos os variados letramentos como concepções pedagógicas e suas potencialidades na abordagem pedagógica do professor. A restrição ou limitação do uso de linguagens artísticas contemporâneas na sala de aula por parte do professor pode estar relacionada, muitas vezes, à falta de formação inicial e continuada, no tocante à necessidade do letramento visual e multiletramentos na contemporaneidade.

Para Stokes (2002), o letramento visual é definido como a habilidade de ler, interpretar e entender a informação apresentada em imagens gráficas ou pictóricas, bem como de transformá-la em imagens e formas que nos auxiliem na comunicação. Por sua vez, para Silvino (2012, p. 13):

De um modo geral, o letrado visual olha uma imagem cuidadosamente e tenta perceber as intenções da mesma. O letramento visual permite que o indivíduo reúna as informações e ideias contidas em um espaço imagético colocando-as no seu contexto, determinando se são válidas ou não para a construção do seu significado. 
Com tantos avanços tecnológicos, além do uso de letramento visual no contexto escolar e social, não há como negar que a prática artística contemporânea, em boa parte das ocasiões, utiliza a tecnologia digital e, por esse viés, para pensar em um letramento na atualidade, devemos considerar a presença das tecnologias em nossa vida cotidiana, ou seja, a construção de um letramento digital se apresenta também como uma necessidade.

Por letramentos digitais, concordamos com Buzato (2006), que afirma serem redes de letramentos (práticas sociais) que se entrelaçam, apoiam-se e se apropriam mútua e continuamente por meio de dispositivos digitais para finalidades específicas em contextos socioculturais limitados fisicamente e naqueles denominados on-line, construídos pela interação social mediada eletronicamente.

O significado de letramento, com o decorrer do tempo, modificou-se, passando a utilizar, conforme Rojo (2013, diferentes termos e conceitos, entre eles: letramento (no singular), tipos e níveis de letramento, letramentos (no plural), práticas de letramento, multiletramentos e, por fim, novos letramentos.

De acordo com o pensamento de Fofonca (2015), os novos letramentos e a própria Pedagogia dos Multiletramentos possibilita articular linguagens que ampliam e hibridizam as práticas pedagógicas contemporâneas, numa mediação entre as diferentes linguagens e os diversos dispositivos tecnológicos. Para além disso, na perspectiva do autor,

[...] o ato de ler envolve articular diferentes modalidades de linguagem além da escrita, como a imagem (estática e em movimento), a fala e a música, refletindo as mudanças sociais e tecnológicas atuais. Este enfoque amplia-se e diversifica-se não só pelas maneiras de disponibilizar e compartilhar informações e conhecimentos, mas também de lê-los e produzi-los. O desenvolvimento do (multi)letramento por meio das linguagens híbridas envolve, contudo, desafios para os leitores e para os agentes que trabalham com as linguagens de um modo geral (FOFONCA, 2015, p. 55).

Diante do posicionamento de Fofonca (2015), ressaltamos que atualmente é necessário para a docência um contexto de aprendizagem submerso nos multiletramentos, visto que o conceito de "multi" exemplifica as muitas formas de letramentos que podemos presenciar na sociedade contemporânea, em que dá a devida importância ao processo de construção do imagético no campo multifacetado das linguagens. Nesse sentido, com o objetivo de esclarecer acerca do processo contextual de formação continuada, no próximo tópico abordaremos a 
discussão em torno da formação dos professores para a adoção dos letramentos e multiletramentos nesse novo currículo que se delineia.

\section{A FORMAÇÃO CONTINUADA E A COLETA DE DADOS}

Na formação ocorrida em maio de 2018, em parceria com a Secretaria Municipal de Educação da cidade de São Bento do Sul, tivemos como público participante dezenove professores, dezoito dos quais concordaram em colaborar com nossa pesquisa, respondendo aos nossos questionários.

A formação foi oferecida para professores efetivos e professores contratados (em caráter temporário), por meio de uma inscrição encaminhada pela Secretaria Municipal a todas as unidades educacionais da rede. Durante a formação, foram aplicados dois questionários em dois momentos distintos da formação: o primeiro no início e o segundo ao final da formação.

Para aprofundarmos os pontos levantados pelos questionários, fizemos também o uso da carta narrativa com o objetivo de os docentes da Educação Básica relatarem como eles observam o uso de atividades pedagógicas voltadas à linguagem fotográfica, oportunizando olhares múltiplos com relação aos letramentos visual e digital.

No primeiro questionário, o objetivo foi a busca de respostas dos seguintes aspectos: 1) idade; 2) concepção apresentada acerca de diferentes as tecnologias e quais destas existem em sua realidade escolar; e, por fim, 3) como era realizado seu planejamento, utilizando a Internet, e se havia algum obstáculo para o uso das tecnologias na escola.

No segundo questionário, a finalidade foi descobrir se os sujeitos tinham o conhecimento do que se tratava a linguagem do Stop Motion e a perspectiva dos participantes sobre a adoção de diferentes linguagens em sala de aula.

Os dados dos questionários permitiram-nos constatar que a grande parte dos participantes tem idade entre 30 e 45 anos e entende a tecnologia como ferramenta facilitadora para a comunicação e a interação com os discentes imersivos em contextos e ambiências digitais. Nesse sentido, a tecnologia digital foi apontada usualmente por meio de mídias físicas, como os próprios smarthpones - dispositivos móveis. Cabe ressaltar, entretanto, que a maioria dos participantes docentes não indicou que esse tipo de tecnologia necessita de acesso à Internet, assim como sustentam os estudos de Camas et al. (2013). 
O termo tecnologia na educação foi concebido pela maioria dos participantes como a utilização de ferramentas e tecnologias no ambiente escolar em favor dos processos de ensino e aprendizagem. Para os participantes, o dispositivo móvel é o tipo de tecnologia mais usada pelos sujeitos que afirmam passar mais de 12 horas por dia conectados à Internet e entendem que ela auxilia na preparação de aulas, tornando-as mais atraentes e dinâmicas, ocasionando, por conseguinte, uma participação mais dialógica e efetiva, mais curiosidade, e aflorando aspectos mais colaborativos entre os discentes.

Nos diálogos das entrevistas e nas relações formativas, a estrutura tecnológica oferecida, bem como a formação para a adoção das tecnologias na escola, foram apontadas como ineficientes, com ausência de bons equipamentos para o desenvolvimento da integração das TD ao currículo de Arte.

No que diz respeito à presença em cursos de extensão, a maioria dos participantes revelou já ter participado. Entretanto, a maior parte dos sujeitos demonstrou não saber do que se tratava a linguagem de animação em Stop Motion, o que nos permite concluir que boa parte do grupo ainda não havia experimentado um curso de formação voltado a essa linguagem. Todavia, a maioria dos sujeitos afirmou já ter utilizado em sala de aula ou experimentado outros tipos de animações nas mesclas de linguagens.

Outro dado muito interessante mencionado pelos participantes foi que, embora a linguagem de animação em Stop Motion ainda não tivesse sido experimentada por eles, é possível aplicá-la em sala de aula e, nesse sentido, os conhecimentos explorados foram extremamente importantes sob a ótica dos participantes.

\section{AS CARTAS NARRATIVAS}

Após a formação dialógica, convidamos um grupo de dez docentes para responderem às cartas narrativas. Selecionamos essa quantidade por acreditarmos que o instrumento de pesquisa baseado nas cartas narrativas é preciso e, portanto, a nosso ver, esse número de participantes nessa etapa seria o suficiente.

Esses sujeitos foram escolhidos levando em conta profissionais temporários e efetivos, os diferentes níveis de ensino e o tempo de serviço desses profissionais em sala de aula. 
Portanto, nosso objetivo era entender como as linguagens artísticas são exploradas tanto pelos profissionais mais antigos quanto pelos mais atuais.

A questão motivadora para os professores escreverem suas percepções foi: "Conte-nos como você observa as atividades pedagógicas voltadas para a linguagem fotográfica nas aulas de Arte, como você entende a exploração do uso do letramento visual nas propostas educativas e quais são os benefícios e obstáculos em sua prática educativa para exploração destes temas".

De acordo com a leitura e análise individual das cartas, os sujeitos consideram o letramento digital como recurso tecnológico, confundindo a concepção e, portanto, não conseguindo inserir na sala de aula propostas que possam auxiliar o processo de ensino e aprendizagem de seus alunos.

Ademais, pudemos verificar que os sujeitos não indicaram ser preciso uma formação continuada para a garantia do desenvolvimento do letramento digital no espaço escolar, pois, de acordo com Melo (2015), temos a necessidade de processos formativos que levem em conta a ótica das mídias na educação, considerando a formação docente não somente atrelada à mídiaeducação, mas também da perspectiva mídia-educativa, tendo em vista uma abordagem crítica dos meios. A formação continuada é também de suma importância para o desenvolvimento de práticas que compreendem o ensino das linguagens e seus multiletramentos (FOFONCA, 2015).

A noção de letramento digital desses sujeitos sugerem que está diretamente ligada ao uso de equipamentos físicos, demonstrando que, muitas vezes, a tecnologia em suas diferentes formas não é explorada na sala de aula em razão da estrutura física oferecida e, portanto, diante desse fator, algumas linguagens artísticas, incluindo a fotografia, não são utilizadas na prática pedagógica desses profissionais.

No tocante ao letramento visual, os sujeitos entendem que esse tipo de letramento é algo intrínseco no processo de ensino e aprendizagem do aluno e no ensino de Arte. Entretanto, nenhum sujeito apontou a importância do processo de mediação pelo professor na construção do letramento visual dos alunos.

Outro fator não revelado pelos sujeitos foi como os alunos fazem a leitura das imagens e como esse processo ocorre na sala de aula. Portanto, por esse motivo, não temos propriedades para dialogar com Dondis (1997), dado que a autora menciona que os recursos visuais utilizados para fins pedagógicos são ineficientes para a compreensão e avaliação dos efeitos que produzem e, consequentemente, o professor não deveria manter-se ingênuo com relação a esse tema. 
Com relação ao uso da linguagem fotográfica no ensino de Arte, os sujeitos entendemna como recurso tecnológico que pode contribuir positivamente nas aulas de Arte e como meio para explorar o visual.

A linguagem fotográfica, segundo as percepções apresentadas pelos sujeitos, pode ser um meio de protagonismo para o aluno expressar-se artisticamente e de reflexão da Arte. Desse modo, torna-se um elemento para explorar diferentes linguagens por se tratar de uma linguagem contemporânea e de fácil acesso, visto que os dispositivos móveis atuais possibilitam que a linguagem fotográfica possa ser trabalhada nas aulas de Arte.

A infraestrutura oferecida na escola pode ser um obstáculo para que a linguagem fotográfica seja explorada em sua totalidade, porquanto, de acordo com uma percepção apresentada, a escola não dispõe de recursos tecnológicos e os alunos atendidos na escola são de baixa renda.

A formação propiciada oportunizou aos sujeitos perceber que a linguagem de animação em Stop Motion pode ser um meio para que a linguagem fotográfica possa ser trabalhada na sala de aula e também um meio para que diferentes linguagens artísticas possam ser exploradas.

No que concerne à percepção dos sujeitos acerca da prática dos multiletramentos, pudemos perceber que o grupo não expressou dispor de práticas multiletradas baseadas em diferentes linguagens, tecnologias, linguagens e semioses (FOFONCA, 2015).

Diante de um leque de possibilidades pedagógicas mediado pelas tecnologias, talvez seja evidente que o grupo, em algum momento na sua prática pedagógica, utilize tais recursos. Entretanto, conforme Fofonca (2015), os professores, embora desenvolvam práticas que compreendam o ensino de multiletramentos e linguagens, para o desenvolvimento desse processo necessitam de formação continuada.

Logo, para a Pedagogia dos Multiletramentos ocorrer, conforme Fofonca (2015), o professor deveria possuir elementos que possibilitem a construção de um olhar interdisciplinar, que o levassem à ressignificação do olhar e ao fazer pedagógico.

\section{CONSIDERAÇÕES FINAIS}

O estudo permitiu ampliarmos nosso olhar com relação ao que nos propomos a investigar. Por conseguinte, possibilitou verificarmos que, por meio da prática pedagógica, as 
diferentes linguagens artísticas podem são exploradas em sala de aula, adotando a fotografia e seus desdobramentos, tais como a animação em Stop Motion. Portanto, os letramentos podem ser utilizados, mas podem não ter sido contemplados na formação inicial e continuada do docente de Arte, o que pode interferir em sua prática pedagógica.

A partir do estudo realizado, foi possível responder à questão que nos trouxe a esta pesquisa, que se constituiu por meio da percepção de um grupo de docente de Arte do Ensino Fundamental, considerando a adoção da linguagem fotográfica e de imagens em sala de aula. Após a leitura e a análise dos questionários e das cartas narrativas, pudemos constatar que os participantes reconhecem a importância da adoção de imagens e a exploração da linguagem fotográfica na prática pedagógica, especialmente no ensino de Arte.

No entanto, no que diz respeito à adoção de imagens na prática pedagógica, os sujeitos não exemplificam como as utilizam e quais os critérios estabelecidos. Portanto, apesar de os sujeitos revelarem que o letramento visual está inserido nos processos de ensino e aprendizagem do aluno, não demonstraram como isso ocorre no processo das aulas de Arte e, assim, não abordaram em suas cartas como é a estrutura oferecida na escola para a exploração do uso dos aspectos imagéticos.

Ao analisarmos as respostas dos sujeitos, verificamos que muitas das descrições remetem à ideia de imagem relacionada ao prazer e à beleza, pouco discorrendo-se sobre as imagens como uma possibilidade de uma leitura crítica da realidade social.

Diante das percepções apresentadas, ficou evidenciado que os sujeitos reconhecem que a fotografia é um tipo de Arte que deve ser trabalhado no contexto pedagógico, todavia poucos participantes apresentaram o modo como trabalham com essa linguagem.

Entre as percepções apresentadas que apontam como a fotografia é explorada na sala de aula, evidenciamos que essa linguagem artística, muitas vezes, é pensada apenas como um mero recurso imagético e ilustrativo para as aulas. Portanto, talvez não tenham sido oportunizados aos participantes, durante a graduação, ou por meio de cursos de formação continuada, conhecimentos suficientes para que a linguagem fotográfica pudesse ser explorada em sala de aula, significando, assim, a função de adoção de um conhecimento necessário nos processos de ensino e aprendizagem na formação dos sujeitos discentes.

Os docentes participantes também demonstraram que muitas escolas não permitem o uso de dispositivos móveis, mesmo que para fins pedagógicos, o que é um fator preocupante, visto que esses equipamentos são um meio para que as diferentes linguagens artísticas possam 
ser exploradas e incorporadas como um objeto temático que se abre a novas aprendizagens, para além do currículo formal.

A presente pesquisa viabilizou-nos compreender que, em virtude de como o ensino de Arte é realizado na atualidade, em especial no lócus pesquisado, diferentes linguagens artísticas devem ser exploradas em sala de aula, assim como a própria sociedade dela faz uso para além dos vínculos pedagógicos e de ensino. Esclarecemos, no entanto, que é possível verificar, por meio da pesquisa, que o professor de Arte não tem formação adequada para que essas linguagens possam ser desenvolvidas no contexto escolarizante. Outro fator é que, muitas vezes, a inserção dessa acepção no currículo se dá somente por intermédio de um único profissional de Arte.

Nesse sentido, observamos que tais linguagens, ao serem contempladas e utilizadas na prática pedagógica, podem não ser exploradas em sua plenitude por não serem consideradas na formação inicial do professor de Arte ou em cursos de formação continuada, nem mesmo discutidas como uma nota de revisão de planejamento pedagógico com fins de incorporação crítica curricular.

Ainda assim, diante dos multiletramentos, do letramento visual e da linguagem fotográfica, acredita-se que um web currículo poderia ampliar as ações pedagógicas que envolvem as distintas linguagens, semioses e culturas estéticas mobilizadoras, mas ainda apresentam uma lacuna faltante num processo formativo mais amplo nas práticas de escolarização sensível. Nesse escopo da discussão curricular, as práticas sociais midiatizadas pelas tecnologias digitais deveriam estar, intrinsecamente, postas na constituição de uma prática pedagógica repensada na/pela docência de Arte.

Ademais, salienta-se que foram destaque nas narrativas docentes a insuficiência da estrutura física do contexto pesquisado, em que muitas vezes há escassez de objetos educacionais digitais, tornando-se um obstáculo para que os multiletramentos possam ser explorados no contexto escolar adequadamente. Ainda nesses aspectos, concordamos que esse conhecimento depende, também, das possibilidades da infraestrutura da escola ou, até mesmo, não existindo, da própria permissão da gestão escolar para o simples uso de ferramentas e/ou elementos tecnológicos para uma participação mais ativa de discentes e docentes na construção de um currículo que repense a prática artística como formação fundamental de cidadãos que 
compreendem o sentido estético e sensível de uma sociedade contemporânea em constante transição.

\section{REFERÊNCIAS}

AFONSO, Diogo Rodrigues. A fotografia como instrumento de educação visual.

Orientador: Marcos Rizolli. 2014. 114 f. Dissertação (Mestrado em Educação, Arte e História da Cultura) - Programa de Pós-Graduação em Arte e História da Cultura, Universidade Presbiteriana Mackenzie, São Paulo, 2014.

ALMEIDA, Maria Elizabeth Bianconcini; VALENTE, José Armando. Currículo e contextos de aprendizagem: integração entre o formal e o não-formal por meio de tecnologias digitais. Revista eCurriculum, São Paulo, v. 12, p. 1162-1188, 2014. Disponível em: https://revistas.pucsp.br/curriculum/article/view/20355/15390. Acesso em: 15 ago. 2018.

BRASIL. Base Nacional Curricular Comum. Ministério da Educação. 2018. Disponível em: http://basenacionalcomum.mec.gov.br/download-da-bncc. Acesso em: 28 ago. 2018.

BUZATO, Marcelo El Khouri. Letramento digital: um lugar para pensar em internet, educação e oportunidades. In: CONGRESSO IBERO-AMERICANO EDUCAREDE, 3., São Paulo, 2006. Anais... São Paulo: CENPEC, 2006.

CAMAS, Nuria Pons Vilardell; MANDAJI, Monica; RIBEIRO, Renata Aquino; MENGALLI, Neli Maria. Professor e cultura digital: reflexão teórica acerca dos novos desafios na ação formadora para o nosso século. Revista Reflexão \& Ação, Santa Cruz do Sul, v. 21, n. 2, p. 179-198, jul./dez. 2013. Disponível em: https://online.unisc.br/seer/index.php/reflex/article/view/3834. Acesso em: 15 out. 2018.

CARVALHO, Jailson Araujo. Tecnologia e ensino de teatro: diálogos para além da sala de aula. Orientador: José Mauro Barbosa Ribeiro. 2017. 128 f. Dissertação (Mestrado Profissional em Artes - Prof-Artes) - Instituto de Artes, Universidade de Brasília, Brasília, 2017.

DONDIS, Donis. A. Sintaxe da linguagem visual. 2. ed. São Paulo: Martins Fontes, 1997.

FOFONCA, Eduardo. Entre as práticas de (multi)letramento e os processos de aprendizagem ubíqua da cultura digital: as percepções estéticas de educadores das linguagens. Orientador: Marcos Rizolli. 2015. 190 f. Tese (Doutorado em Educação, Arte e História da Cultura) - Programa de Pós-Graduação em Arte e História da Cultura, Universidade Presbiteriana Mackenzie, São Paulo, 2015.

GALKOWSKI, Andrei Rafael. A fotografia e a linguagem de animação na formação do professor de arte: entre percepções da linguagem fotográfica, os letramentos do digital e da visualidade na Educação Básica. Orientadora: Núria Pons Vilardell Camas. 2019. 156 f. Dissertação (Mestrado Profissional em Educação) - Programa de Pós-Graduação em Educação, Universidade Federal do Paraná, Curitiba, 2019. 
MACIEL, Viviane Cristina Carmo. Arte multiconectada: o pensamento do professor de arte, as tecnologias de informação e comunicação, as diferentes formas de letramento e a educação. Orientadora: Núria Pons Vilardell Camas. 2016. 207 f. Dissertação (Mestrado em Educação) - Programa de Pós-Graduação em Educação, Universidade Federal do Paraná, Curitiba, 2016.

MAGALHÃES, Marcos. Cartilha Anima Escola: técnicas de animação para professores e alunos. 2. ed. Rio de Janeiro: Ideia, 2015.

MELO, Charlote França Rieger Neves de Couto. Mídia-educação e professores: pensando sobre formação continuada a partir da apropriação das mídias na educação. Orientadora: Glaucia da Silva Brito. 2015. 178 f. Dissertação (Mestrado em Comunicação) - Programa de Pós-Graduação em Comunicação, Universidade Federal do Paraná, Curitiba, 2015.

PADUAN, Caio; PRESTO, Rafael; PRATES, Valquiria. Ligamundo: Arte 5. ${ }^{\circ}$ ano: Ensino Fundamental: anos iniciais. São Paulo: Saraiva, 2017.

PILLOTTO, Silvia Sell Duarte; PEREIRA, Leda; ROPELATO, Carla Clauber da Silva. Uma educação pela infância: diálogo com o currículo do $1 .^{\circ}$ ano do ensino fundamental. Joinville: Editora Univille, 2009.

PURVES, Barry. Stop Motion. Porto Alegre: Artmed, 2011.

ROJO, Roxane; MOURA, Eduardo (Org.). Multiletramentos na escola. São Paulo: Parábola Editorial, 2012.

ROJO, Roxane. Entrevista multiletramentos, multilinguagens, novas aprendizagens. Acervo do Grupo de Pesquisa relação infância, adolescência e mídia, UFC, 2013. Disponível em: http://www.grim.ufc.br/index.php?option=com_content $\& v i e w=$ article\&id=80:entrevistacom-roxane-rojo-multiletramentos-multilinguagens-eaprendizagens\&catid=8: publicacoes\&Itemid=19. Acesso em: 12 out. 2019.

SILVINIO, F. F. Letramento Visual. ANAIS - Seminários Teóricos Interdisciplinares do SEMIOTEC - I STIS. Nov/2012. Disponível em: http://www.periodicos.letras.ufmg.br/index.php/stis/article/view/2116. Acesso em: 25 out. 2018.

STOKES, Suzanne. Visual literacy in teaching and learning: a literature perspective.

Electronic Journal for the Integration of Technology in Education, v. 1, n. 1, 2002. Disponível em: https://wcpss.pbworks.com/f/Visual+Literacy.pdf. Acesso em: 15 out. 2019.

ZUBLER, Edili Priciliana Pavanelli; ZANIN, Jeferson Lucas; AYRES, Sandra Regina Braz. Stop Motion: formação continuada para seu uso no processo ensino e aprendizagem. 21. ${ }^{\circ}$ Seminário de Educação, Tecnologia e Sociedade. Taquara: Faccat, 2016. Disponível em: https://seer.faccat.br/index.php/redin/article/view/450. Acesso em: 18 out. 2019. 
Recebido em: 12/04/2020

Aprovado em: 09/06/2020 